\title{
Downregulation of MIAT reduces the proliferation and migratory and invasive abilities of retinoblastoma cells by sponging miR-665 and regulating LASP1
}

\author{
XIABING XU, YADONG ZHAO, GANG DUAN and BO DU \\ Department of Ophthalmology, No. 215 Hospital of Shaanxi Nuclear Industry, Xianyang, Shaanxi 712000, P.R. China
}

Received September 24, 2020; Accepted April 28, 2021

DOI: $10.3892 /$ etm.2021.10777

\begin{abstract}
Long non-coding RNAs (lncRNAs) can function as onco-lncRNAs in several types of human cancer, including retinoblastoma $(\mathrm{Rb})$. The present study investigated the potential role and regulatory mechanism of the lncRNA myocardial infarction-associated transcript (MIAT) in Rb. To do so, the expression levels of MIAT, microRNA (miR)-665, and LIM and $\mathrm{SH} 3$ protein 1 (LASP1) in Rb tissues from patients or $\mathrm{Rb}$ cells were analysed using reverse transcription quantitative PCR. The interactions between miR-665 and MIAT/LASP1 were confirmed by the dual-luciferase reporter assay. MTT, Transwell (to assess migration and invasion) and western blotting assays were used to explore the functions of the MIAT/miR-665/LASP1 axis on Rb progression in vitro. The results of the present study indicated that MIAT targeted miR-665. In Rb tissues and cell lines, high expression of MIAT was observed, whereas miR-665 was downregulated in $\mathrm{Rb}$ tissues. Furthermore, the proliferation and migratory and invasive abilities of Rb Y79 and HXO-RB44 cells were decreased following MIAT downregulation or miR-665 overexpression. In addition, LASP1 was identified as a target gene of miR-665. Both the decreased expression of miR-665 and the elevated expression of LASP1 reversed the suppressive effects of MIAT knockdown on the proliferation and migratory and invasive abilities of Y79 cells. Furthermore, MIAT silencing attenuated the development of $\mathrm{Rb}$ by regulating the miR-665/LASP1 axis. Taken together, these findings suggested that MIAT may be considered as a possible therapeutic target for $\mathrm{Rb}$.
\end{abstract}

\section{Introduction}

Retinoblastoma $(\mathrm{Rb})$ is a common malignant tumour reported mainly in children and affecting $~ 8,000$ infants worldwide

Correspondence to: Dr Bo Du, Department of Ophthalmology, No. 215 Hospital of Shaanxi Nuclear Industry, 35 Weiyang West Road, Xianyang, Shaanxi 712000, P.R. China

E-mail: dubo312@163.com

Key words: retinoblastoma, long non-coding RNA myocardial infarction associated transcript, miR-665, LIM and SH3 protein 1 annually (1). Rb morbidity rate in developed countries is lower than that observed in underdeveloped countries, suggesting that $\mathrm{Rb}$ morbidity is closely associated with effective diagnosis and treatment $(2,3)$. At present, the main treatments of $\mathrm{Rb}$ include enucleation, laser photocoagulation, chemotherapy and focal therapy (4). However, the therapeutic effects remain limited due to accelerated metastasis formation in $\mathrm{Rb}(5)$. It is therefore crucial to determine effective therapeutic targets for $\mathrm{Rb}$ to diminish the formation of metastasis.

Long non-coding RNAs (lncRNAs) are defined as transcripts of $>200$ nucleotides in length (6). Certain lncRNAs have been reported to contribute considerably to the pathogenesis of Rb, including LINC00152 (7), small nucleolar RNA host gene 16 (SNHG16) (8), Pvt1 oncogene (PVT1) (9) and TP73 antisense RNA (TP73-AS1) (10). Yang et al (8) demonstrated that SNHG16 downregulation can restrain Rb cell migratory and invasive abilities. Wu et al (9) reported that PVT1 silencing not only suppresses the proliferation and migratory and invasive abilities of Rb cells in vitro, but also inhibits the growth of tumour xenografts in vivo. Wang et al (10) reported increased expression of TP73-AS1 in Rb tissues and cell lines (Y79, HXO-RB44, WERI-Rb-1 and SO-RB50), whereas TP37-AS1 overexpression could further aggravate the malignant phenotype of $\mathrm{Rb}$ in vitro (10). All the aforementioned lncRNAs serve as oncogenes in Rb. In addition, the lncRNA myocardial infarction-associated transcript (MIAT) was demonstrated to facilitate the progression of numerous types of human cancer, including cholangiocarcinoma (CCA) (11), non-small cell lung cancer (NSCLC) $(12,13)$, cervical cancer (CC) (14), ovarian cancer (OC) (15), colorectal cancer (CRC) (16) and gastric cancer (GC) (17). However, the potential role and underlying mechanism of MIAT in $\mathrm{Rb}$ remain unclear.

MicroRNAs (miRNAs/miRs) are a class of small endogenous RNA that can target the 3'-untranslated region to regulate gene expression (18). The anti-tumour roles of certain miRNAs in human cancer, especially in Rb, including miR-22-3p (19), miR-124 (20), miR-182-5p (8), miR-128-3p (8), miR-488-3p (9), miR-506-3p (21) and miR-936 (22), have received increased attention. Furthermore, miR-665 has been reported to serve a crucial role in inhibiting $\mathrm{Rb}$ function $(23,24)$. A recent study demonstrated that miR-665 exerts its inhibitory effect on $\mathrm{Rb}$ by inactivating the Wnt/ $\beta$-catenin pathway (23). In addition, miR-665 regulation by LINC00205 has been demonstrated to restrain $\mathrm{Rb}$ tumorigenesis (24). The modulation of miR-665 
activity by MIAT during $\mathrm{Rb}$ progression requires therefore further investigation.

LIM and SH3 protein 1 (LASP1) is an oncogene in the pathogenesis of several human cancers, such as hepatocellular carcinoma (HCC) (25), CRC (26), prostate cancer (27) and breast cancer (28). In these cancers, LASP1 has been indicated to be regulated by miRNAs involved in cancer progression $(25,29)$. Hu et al $(25)$ revealed that miR-326 repressed the cell proliferation and invasion of HCC via directly targeting LASP1. Song et al (29) demonstrated that LASP1 is a downstream target of miR-342-3p affecting the progression of oral squamous cell carcinoma. In addition, Yang et al (8) demonstrated that IncRNA SNHG16 promoted the migration and invasion of Rb cells by regulating LASP1. Furthermore, interestingly, Liu et al (30) indicated that MIAT interacted with LASP1 in the development of papillary thyroid cancer. Nevertheless, the association between miR-665 and LASP1, as well as the role of the MIAT/miR-665/LASP1 axis in the pathogenesis of $\mathrm{Rb}$, are largely unknown.

In the present study, the expression levels of MIAT, miR-665 and LASP1 in Rb tissues and cells were analysed. The detailed regulatory mechanisms of the MIAT/miR-665/LASP1 axis in the pathogenesis of $\mathrm{Rb}$ were also explored. The findings from this study may provide a possible therapeutic target for $\mathrm{Rb}$.

\section{Materials and methods}

Patients with $R b$. A total of 47 patients with $\mathrm{Rb}$ (age range, 4 months to 14 years; mean age, $5.54 \pm 3.09$ years) were enrolled in the No. 215 Hospital of Shaanxi Nuclear Industry (Xianyang, China) between March 2017 and July 2019. The Rb tissues and adjacent normal tissues $(1 \mathrm{~cm}$ from the edge of the tumour tissues) were collected following an enucleation procedure. Tumour tissues were histologically confirmed and the adjacent tissues without histopathological changes were considered as the normal control group. None of the patients received any preoperative radiotherapy and/or chemotherapy. Each patient or their parents provided written informed consent. The protocol was approved by the Ethics Committee of the No. 215 Hospital of Shaanxi Nuclear Industry (approval no. EC-20200924-1017).

Cell culture and transfection. The human retinal epithelial ARPE-19 cell line and the human Rb Y79, HXO-RB44, WERI-Rb-1 and SO-RB50 cell lines were obtained from the American Type Culture Collection. These cell lines were selected according to previous studies (9,31-34). All cells were cultured in Dulbecco's modified Eagle's medium (DMEM; Invitrogen; Thermo Fisher Scientific, Inc.) containing $10 \%$ FBS (Gibco; Thermo Fisher Scientific, Inc.) and placed at $37^{\circ} \mathrm{C}$ in a humidified incubator containing $5 \% \mathrm{CO}_{2}$.

The plasmids used in the present study were synthesised by Hanbio Biotechnology Co., Ltd. and included the short hairpin (sh)RNA-MIAT (sh-MIAT; 5'-UCCUCCGAACCUGGCA CGU-3'), shRNA-negative control (sh-NC; 5'-UUCUCCGAAC GUGUCACGU-3'), miR-665 mimics (5'-ACCAGGAGGCU GAGGCCCCU-3'), mimics-NC (miR-NC; 5'-UUCUCCGAA CGUGUCACGUTT-3'), miR-665 inhibitor (5'-AGGGGCCU CAGCCUCCUGGU-3'), inhibitor NC (5'-CAGUACUUUUGU GUAGUACAA-3'), LASP1 overexpression vector (pcDNALASP1) and pcDNA-negative control (pcDNA-NC).
Transfections (all the above molecules at $20 \mathrm{nM}$ ) were performed using Lipofectamine ${ }^{\circledR} 3000$ (Thermo Fisher Scientific, Inc.) according to the manufacturers' instructions. After $48 \mathrm{~h}$, cells were collected for subsequent experiments.

Reverse transcription-quantitative (RT-q)PCR. Total RNA was extracted from Rb tissues and the Y79, HXO-RB44, WERI-Rb-1 and SO-RB50 cell lines using TRIzol ${ }^{\circledR}$ (Invitrogen; Thermo Fisher Scientific, Inc.). According to the manufacturer's instructions, RNA was reversed transcribed into cDNA using the First-Strand cDNA Synthesis kit (APeXBIO Technology LLC). RT-qPCR was performed using the SYBR-Green FAST Mastermix (Qiagen $\mathrm{GmbH}$ ). The following thermocycling conditions were used for the qPCR: Initial denaturation at $95^{\circ} \mathrm{C}$ for $3 \mathrm{~min}$, followed by 40 cycles at $95^{\circ} \mathrm{C}$ for $15 \mathrm{sec}$ (denaturation), $60^{\circ} \mathrm{C}$ for $30 \mathrm{sec}$ (annealing), $72^{\circ} \mathrm{C}$ for $1 \mathrm{~min}$ (elongation) and a final extension at $72^{\circ} \mathrm{C}$ for $5 \mathrm{~min}$. GADPH and U6 were used as internal references. The relative expression levels were normalized to endogenous control and were expressed as $2^{-\Delta \Delta \mathrm{Cq}}(35)$. The respective sequences of primers were as follows: MIAT forward, 5'-TCTTCATGTCAGAACACGCTTTA-3' and reverse, 5'-AAGGTCACCCGAGGTCCAA-3'; miR-665 forward, 5'-GCCGAGACCAGGAGGCTGAG-3' and reverse, 5'-CTCAACTGGTGTCGTGGA-3'; LASP1 forward, 5'-GGT GCGGCAAGATCGTGTA-3' and reverse, 5'-TGCAGGTCT CGCAATGGAA-3'; GAPDH forward, 5'-CCAGGTGGTCTC CTCTGA-3' and reverse, 5'-GCTGTAGCCAAATCGTTGT-3'; and U6 forward, 5'-CTCGCTTCGGCAGCACA-3' and reverse, 5'-AACGCTTCACGAATTTGCGT-3'.

MTT assay. Cells were cultured in 96-well plates at a density of $5 \times 10^{4}$ cells $/ \mathrm{ml}$ for $96 \mathrm{~h}$, followed by addition of $15 \mu \mathrm{l}$ MTT (Procell Life Science \& Technology, Co., Ltd.) and incubation for $2 \mathrm{~h}$ at $37^{\circ} \mathrm{C}$. Subsequently, $100 \mu \mathrm{l}$ DMSO was added to dissolve the formazan. The optical density was measured at $570 \mathrm{~nm}$ using a microplate reader (Thermo Fisher Scientific, Inc.).

Migration and invasion assays. For the migration assay, transfected Y79 and HXO-RB44 cells $\left(5 \times 10^{4}\right.$ cells $\left./ \mathrm{ml}\right)$ were re-suspended in serum-free DMEM and seeded in the upper chamber of a Transwell insert ( $8 \mu \mathrm{m}$ pore size; BD Biosciences). Simultaneously, DMEM containing 10\% FBS was added in the lower chamber. For the invasion assay, Matrigel matrix (Becton-Dickinson and Company) was used to coat the membranes before cell seeding. Following overnight incubation at $37^{\circ} \mathrm{C}$, cells in the lower chamber were fixed with $4 \%$ paraformaldehyde at $37^{\circ} \mathrm{C}$ for $1 \mathrm{~h}$ and stained with $0.1 \%$ crystal violet for $15 \mathrm{~min}$ at $37^{\circ} \mathrm{C}$. The stained cells were imaged using an inverted light microscope (Olympus Corporation) and analysed with ImageJ software (version 1.46; National Institutes of Health).

Dual luciferase reporter (DLR) assay. The targeting association between MIAT and miR-665 was analyzed using the StarBase software (version 2.0; http://starbase.sysu.edu.cn). Additionally, the targeting interaction between miR-665 and LASP1 was predicted using TargetScan software (v7.2; http://www.targetscan.org/vert_72/). The predicted binding region sequences (MIAT, 5'-GGGUUCCAGGCUCCUGG-3'; 
LASP1, 5'-CUCCUGGU-3') were inserted into pGL3 vector (PromegaCorporation)toconstructthewild-type(wt)phenotype. For construction of the mutant (mut) phenotype, the mutation sequences (MIAT mut, 5'-CCCUUCGUCGGAGGACC-3'; LASP1 mut, 5'-GAGGACCA-3') were inserted into pGL3. Y79 and HXO-RB44 cells were then co-transfected with MIAT/LASP1-wt or MIAT/LASP1-mut (80 ng) and miR-665 mimics/miR-NC $(50 \mathrm{nM})$ using Lipofectamine 3000 (Invitrogen; Thermo Fisher Scientific, Inc.) at $37^{\circ} \mathrm{C}$ for $48 \mathrm{~h}$, followed by detection of the luciferase activity using a dual-luciferase reporter assay system (Promega Corporation). The activity of firefly luciferase was normalized to that of Renilla luciferase.

Western blotting. Transfected cells were lysed on ice with RIPA (Beyotime Institute of Biotechnology) containing $10 \mathrm{mmol} / \mathrm{l}$ PMSF (Beyotime Institute of Biotechnology). The protein concentration was detected using a BCA Protein Assay Kit (Abcam). A total of $50 \mu \mathrm{g}$ of protein/lane was separated via $10 \%$ SDS-PAGE and transferred onto PVDF membranes. Following blocking with 5\% skimmed milk for $2 \mathrm{~h}$ at $25^{\circ} \mathrm{C}$, membranes were incubated with the primary antibodies against LASP1 (1:1,000; cat. no. SAB1402251; Sigma-Aldrich; Merck KGaA) and $\alpha$-tubulin (1:1,000; cat. no. T6199; Sigma-Aldrich; Merck KGaA) at $4^{\circ} \mathrm{C}$ overnight. Membranes were then incubated with the HRP-conjugated anti-mouse IgG secondary antibody (1:5,000; cat. no. sc-2005; Santa Cruz Biotechnology, Inc.) for $1 \mathrm{~h}$ at $37^{\circ} \mathrm{C}$. Bands were detected using enhanced chemiluminescence substrate (Amersham; Cytiva). Relative expression level of LASP1 was normalized to endogenous control $\alpha$-tubulin. The immunoblots were visualized using an ECL detection kit (Thermo Fisher Scientific, Inc.) using Gel-Pro analyzer (version 4.0; Media Cybernetics, Inc.).

Statistical analysis. The SPSS 20.0 software (IBM Corp.) was used to perform statistical analysis. All cell experiments were performed three times. Data are presented as the mean \pm standard deviation. Student's t-test was used to assess the differences between two groups. One-way ANOVA followed by Tukey's post hoc test was used to evaluate the differences among multiple groups. $\chi^{2}$ test was used to analyse data from Table I. The linear correlation was assessed by Pearson's correlation analysis. $\mathrm{P}<0.05$ was considered to indicate a statistically significant difference.

\section{Results}

High MIAT expression is observed in Rb tissues and cells. The expression of MIAT was initially detected in Rb tissues using RT-qPCR. The results demonstrated that MIAT expression was upregulated in $\mathrm{Rb}$ tissues compared with that in adjacent tissues (Fig. 1A; P<0.01). Furthermore, a significantly increased expression level of MIAT was observed in the tissues from patients with Tumour-Node-Metastasis (TNM) stage III/IV compared with that in the tissues from patients with TNM stage I/II (Fig. 1B; P $<0.01$ ). As shown in Table I, MIAT expression was significantly associated with intraocular international retinoblastoma classification (IIRC) stage $(\mathrm{P}=0.0035)$, TNM stage $(\mathrm{P}=0.012)$ and optic nerve invasion
Table I. Association between MIAT expression and the clinicopathological characteristics of patients with retinoblastoma.

\begin{tabular}{|c|c|c|c|c|}
\hline \multirow[b]{2}{*}{ Characteristics } & \multirow[b]{2}{*}{ Total, $\mathrm{n}$} & \multicolumn{2}{|c|}{ MIAT expression, $\mathrm{n}$} & \multirow[b]{2}{*}{ P-value } \\
\hline & & $\begin{array}{c}\text { Low } \\
(n=23)\end{array}$ & $\begin{array}{l}\text { High } \\
(n=24)\end{array}$ & \\
\hline Age, years & & & & 0.192 \\
\hline$<5$ & 20 & 12 & 8 & \\
\hline$\geq 5$ & 27 & 11 & 16 & \\
\hline $\operatorname{Sex}$ & & & & 0.891 \\
\hline Male & 22 & 11 & 11 & \\
\hline Female & 25 & 12 & 13 & \\
\hline Tumor size, mm & & & & 0.440 \\
\hline$<10$ & 28 & 15 & 13 & \\
\hline$\geq 10$ & 19 & 8 & 11 & \\
\hline Optic nerve invasion & & & & 0.044 \\
\hline No & 30 & 18 & 12 & \\
\hline Yes & 17 & 5 & 12 & \\
\hline TNM stage & & & & 0.012 \\
\hline $\mathrm{I} / \mathrm{II}$ & 18 & 13 & 5 & \\
\hline III/IV & 29 & 10 & 19 & \\
\hline IIRC stage & & & & 0.0035 \\
\hline Early stages (A-C) & 15 & 12 & 3 & \\
\hline $\begin{array}{l}\text { Advanced stages } \\
(\mathrm{D} \text { and } \mathrm{E})\end{array}$ & 32 & 11 & 21 & \\
\hline
\end{tabular}

TNM, Tumor-Node-Metastasis; IIRC, intraocular international retinoblastoma classification; $\mathrm{Rb}$, retinoblastoma; MIAT, MIAT, myocardial infarction-associated transcript.

$(\mathrm{P}=0.044)$. In addition, MIAT mRNA expression was detected in the Rb WERI-Rb-1, SO-RB50, HXO-RB44 and Y79 cell lines, and the normal ARPE-19 cell line. The results from RT-qPCR demonstrated that MIAT expression level was significantly increased in all $\mathrm{Rb}$ cell lines compared with that in the ARPE-19 cell line (Fig. 1C; P<0.01). Since the Y79 and HXO-RB44 cell lines exhibited the highest MIAT expression levels amongst all $\mathrm{Rb}$ cell lines, they were selected for subsequent experiments.

MIAT knockdown inhibits the proliferation and migratory and invasive abilities of $R b$ cells in vitro. To explore the effects of MIAT on Rb progression in vitro, Y79 and HXO-RB44 cells were transfected with sh-MIAT or sh-NC and the transfection efficiency was detected by RT-qPCR. The results demonstrated that the expression level of MIAT was significantly decreased following transfection with sh-MIAT compared with sh-NC, which confirmed the successful transfection into Y79 and HXO-RB44 cells (Fig. 2A; P<0.01). Subsequently, transfected $\mathrm{Y} 79$ and HXO-RB44 cells were used to determine the proliferation and migratory and invasive abilities of $\mathrm{Rb}$ cells using MTT assay and Transwell assay. As presented in Fig. 2B, Y79 and HXO-RB44 cell proliferation was significantly decreased following transfection with sh-MIAT 
A

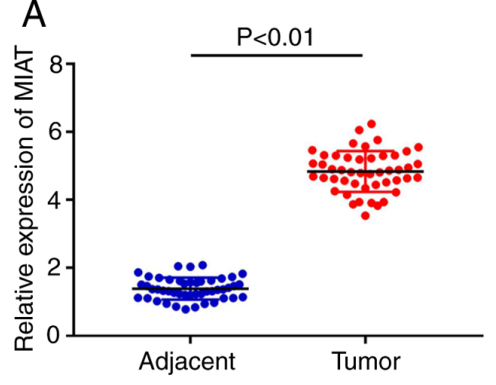

B

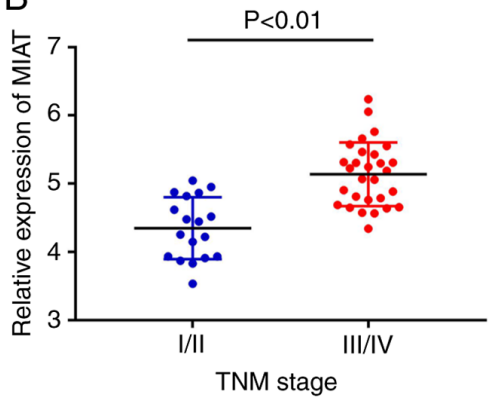

C

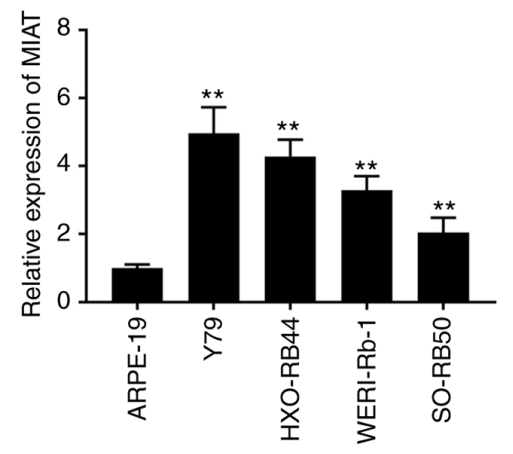

Figure 1. High expression of MIAT is detected in Rb tissues and cells. (A) Expression of MIAT in Rb tissues ( $\mathrm{n}=47$ ) and adjacent tissues ( $\mathrm{n}=47$ ) was detected by RT-qPCR. (B) Expression of MIAT at different TNM stages was detected by RT-qPCR. (C) Expression of MIAT in Y79, HXO-RB44, WERI-Rb-1, SO-RB50 and ARPE-19 cells was detected by RT-qPCR. ${ }^{* *} \mathrm{P}<0.01$ vs. ARPE-19 cell group. Rb, retinoblastoma; MIAT, myocardial infarction-associated transcript; RT-qPCR, reverse transcription-quantitative PCR; TNM, Tumour-Node-Metastasis.

compared with that in the sh-NC group $(\mathrm{P}<0.01)$. Furthermore, both migratory and invasive abilities of $\mathrm{Rb}$ cell lines were decreased in the sh-MIAT group compared with those in the sh-NC group (Fig. 2C and D; $\mathrm{P}<0.01$ ).

MIAT acts as an endogenous sponge of $m i R-665$. IncRNAs can act as competing endogenous RNAs or sponges of miRNAs to modulate cancer progression (36). Through the StarBase software, 58 target miRNAs of MIAT were predicted (data not shown). In the present study, miR-665 was selected due to its important role in $\mathrm{Rb}(23,24)$ (Fig. 3A). A DLR assay was used to confirm the target relationship between MIAT and miR-665 in Y79 and HXO-RB44 cells. The results demonstrated that the luciferase activity in MIAT wt/miR-665 mimics was decreased, which was not the case in the MIAT mut (Fig. 3B; $\mathrm{P}<0.01)$. The results from RT-qPCR indicated that the expression levels of MIAT and miR-665 in Rb cell lines (Fig. 3C; $\mathrm{P}<0.01$ ) and $\mathrm{Rb}$ tissues (Fig. 3E; $\mathrm{P}=0.001, \mathrm{r}=-0.4614$ ) were negatively correlated. In addition, a decreased expression level of miR-665 was detected in $\mathrm{Rb}$ tissues compared with that in the adjacent tissues (Fig. 3D; $\mathrm{P}<0.01$ ).

High expression of miR-665 serves as a suppressor of the proliferation and migratory and invasive abilities of Rb cells in vitro. Both miR-665 mimics and miR-665 inhibitor were transfected into Y79 and HXO-RB44 cells, and the effects of miR-665 overexpression on $\mathrm{Rb}$ progression in vitro were subsequently evaluated. The results demonstrated that miR-665 was significantly upregulated following transfection with miR-665 mimics, whereas it was significantly downregulated following transfection with miR-665 inhibitor (Fig. 4A; $\mathrm{P}<0.01$ ). Similar to the effects of MIAT knockdown on the progression of $\mathrm{Rb}$ in vitro, the results from the MTT assay and Transwell assay revealed that the proliferation and migratory and invasive abilities of $\mathrm{Rb}$ cells were inhibited following miR-665 overexpression (Fig. 4B-D; $\mathrm{P}<0.01$ ).

LASP1 is a downstream target gene of miR-665. As illustrated in Fig. 5A, the TargetScan software predicted a binding site between miR-665 and LASP1. A DLR assay was subsequently used to confirm the binding relationship, and a decrease in luciferase activity in the LASP1 wt/miR-665 mimics groups was observed in both Y79 and HXO-RB44 cells (Fig. 5B; $\mathrm{P}<0.01)$. Furthermore, LASP1 was overexpressed in Rb tissues compared with that in adjacent tissues (Fig. 5C; $\mathrm{P}<0.01$ ). In addition, the results from Pearson's correlation analysis demonstrated a negative correlation between LASP1 and miR-665 expression (Fig. 5D; $\mathrm{P}<0.01, \mathrm{r}=-0.4738$ ); however, a positive correlation was observed between LASP1 and MIAT expression (Fig. 5E; $\mathrm{P}<0.01, \mathrm{r}=0.4116$ ) in $\mathrm{Rb}$ tissues. To further verify the interaction between the expression of miR-665 and LASP1, western blotting was performed to determine the protein expression of LASP1 following transfection of Y79 and HXO-RB44 cells with miR-665 mimics. The results revealed that LASP1 protein expression was decreased following miR-665 upregulation (Fig. 5F; $\mathrm{P}<0.01$ ).

MIAT knockdown decreases the development of $R b$ by sponging miR-665 and regulating LASP1. The results from western blotting revealed that LASP1 expression was increased following transfection with pcDNA-LASP1 (Fig. 6A; $\mathrm{P}<0.01$ ). The results from MTT assay and Transwell assay demonstrated that the suppressive effects of sh-MIAT on the proliferation and migratory and invasive abilities of Y79 and HXO-RB44 cells (Fig. 2) were reversed following transfection with miR-665 inhibitor or pcDNA-LASP1 (Fig. 6B-D; P<0.01).

\section{Discussion}

Chemotherapy and radiation are not the optimal therapy strategies for $\mathrm{Rb}$ as most of the patients with $\mathrm{Rb}$ are children or infants and these therapies can cause serious physical injury (8). Determining a novel therapeutic target for $\mathrm{Rb}$ is therefore essential. Growing evidence has demonstrated that certain $\operatorname{lncRNAs}$ are upregulated in $\mathrm{Rb}$ and are associated with some pathological features of $\mathrm{Rb}$, such as the association between XIST and TNM stage (34), the association of AFAP1-AS1 with choroidal invasion and optic nerve invasion (37), the association of SNHG16 with choroidal invasion, optic nerve invasion and TNM stage (8), and the association of PVT1 with optic nerve invasion and IIRC stage (9). The present study demonstrated that MIAT was overexpressed in $\mathrm{Rb}$ tissues and cell lines. Furthermore, MIAT expression was significantly associated with IIRC stage, TNM stage and 

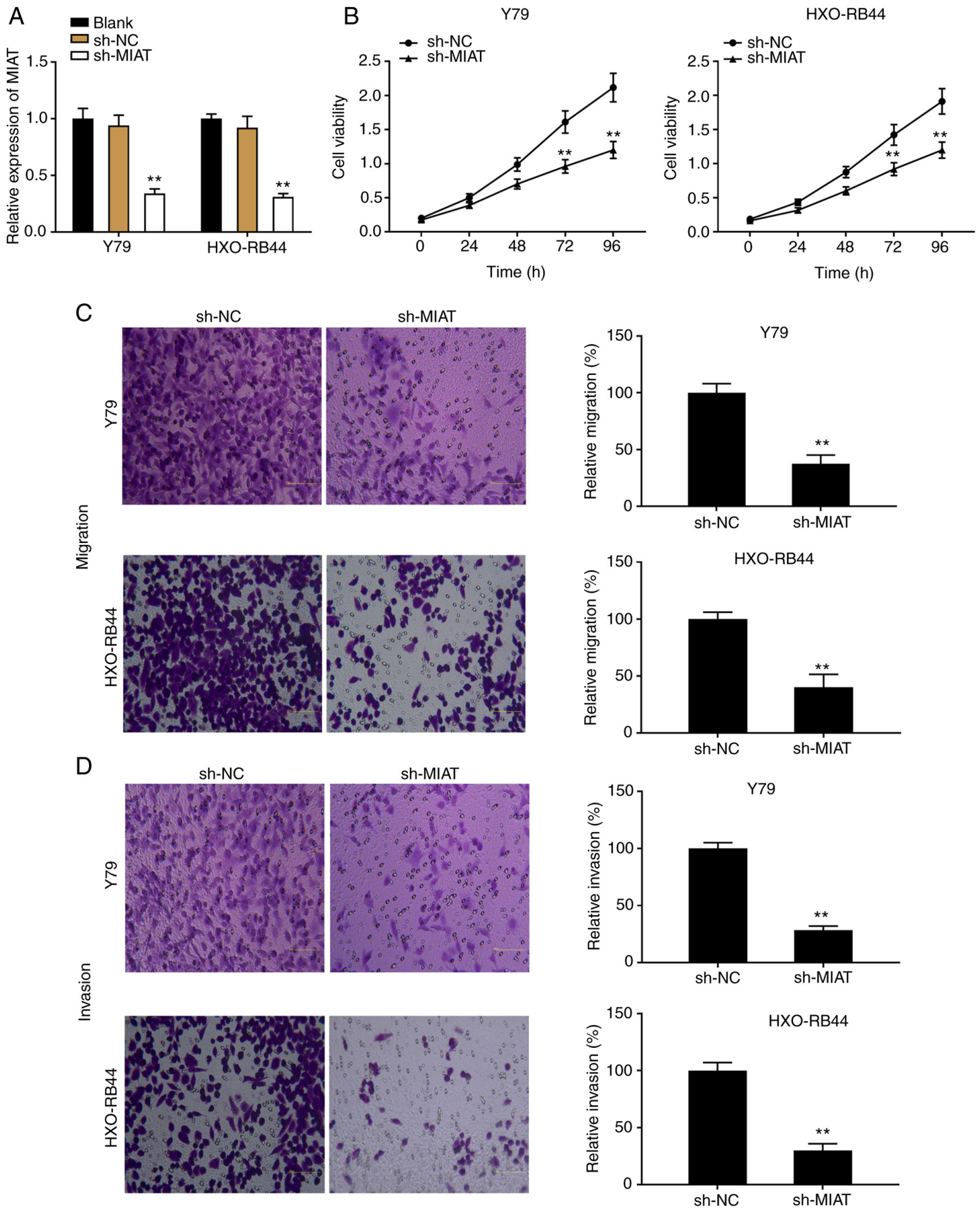

Figure 2. MIAT knockdown inhibits the proliferation and migratory and invasive abilities of Rb cell lines in vitro. (A) Expression of MIAT in Rb cells after transfection with sh-MIAT was detected by reverse transcription-quantitative PCR. (B) Rb cell viability was evaluated using MTT assay. (C) Migratory ability of $\mathrm{Rb}$ cells was measured by Transwell assay. (D) Invasive ability of Rb cells was measured by Transwell assay. ${ }^{* *} \mathrm{P}<0.01 \mathrm{vs}$. sh-NC group. Rb, retinoblastoma; sh, short hairpin; NC, negative control; MIAT, myocardial infarction associated transcript; OD, optical density.

optic nerve invasion. These findings suggested that MIAT may be considered as a risk factor in $\mathrm{Rb}$ and therefore a potential target for treating $\mathrm{Rb}$.

To further explore the possible effect of MIAT on the pathogenesis of $\mathrm{Rb}$, sh-MIAT was transfected into Y79 and HXO-RB44 cells. The results demonstrated that the proliferation and migratory and invasive abilities of $\mathrm{Rb}$ cells were suppressed following MIAT knockdown. Similarly, MIAT has been reported to slow tumorigenesis in several types of human cancer, such as CCA, NSCLC and CC (11-14). Chang et al (11) demonstrated that MIAT silencing can inhibit the proliferation and accelerate the apoptosis of CCA cells. Similar to the findings reported by Zhou et al (12), Li et al (13) reported that transfection with sh-MIAT inhibits the proliferation, migratory and invasive abilities of NSCLC cells. Similar results were reported in a study by Zhang et al (14), which 

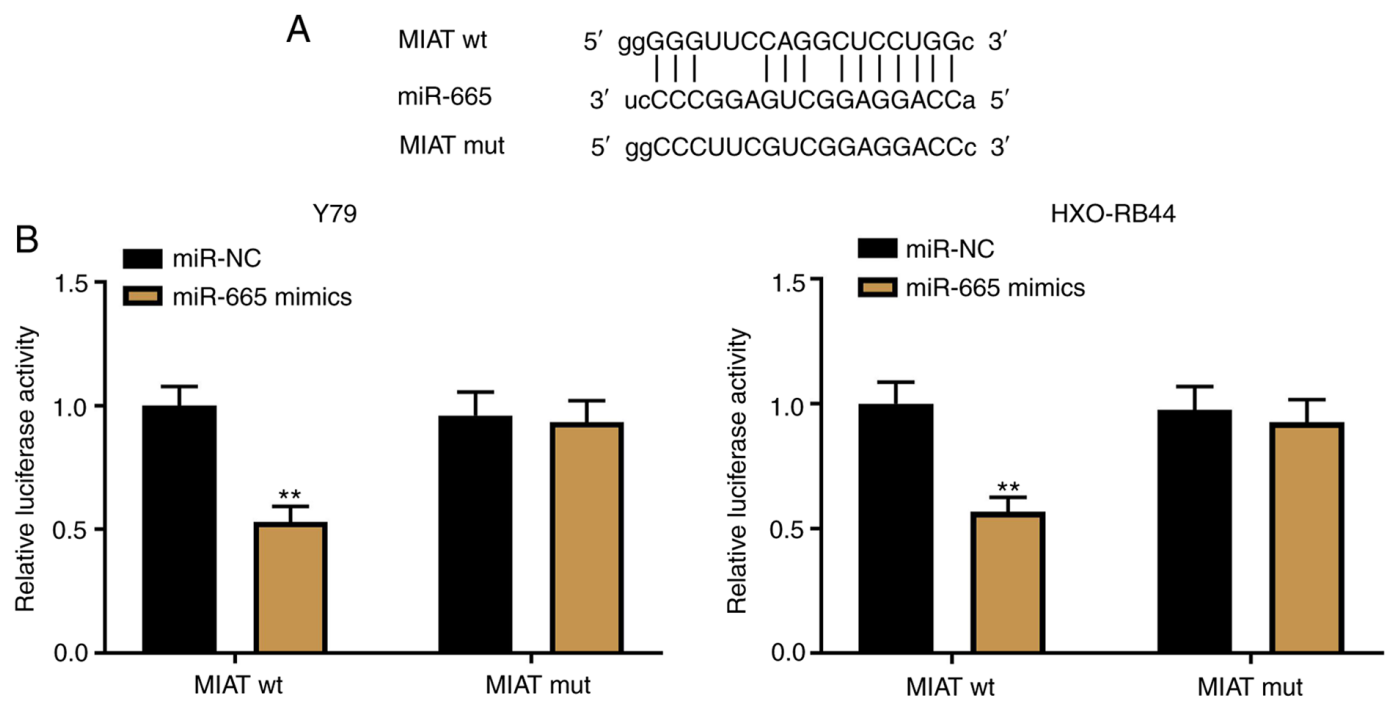

C $\quad$ Y79

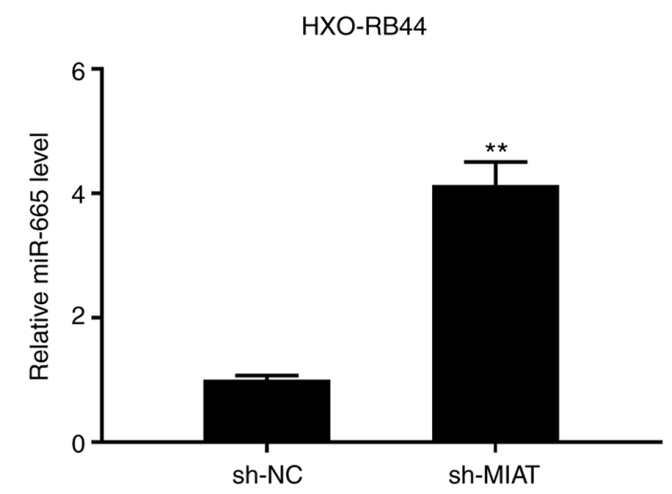

$\mathrm{D}$

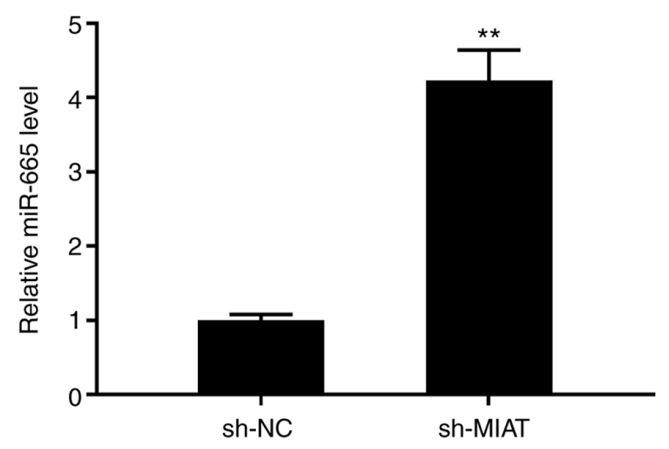

$\mathrm{E}$
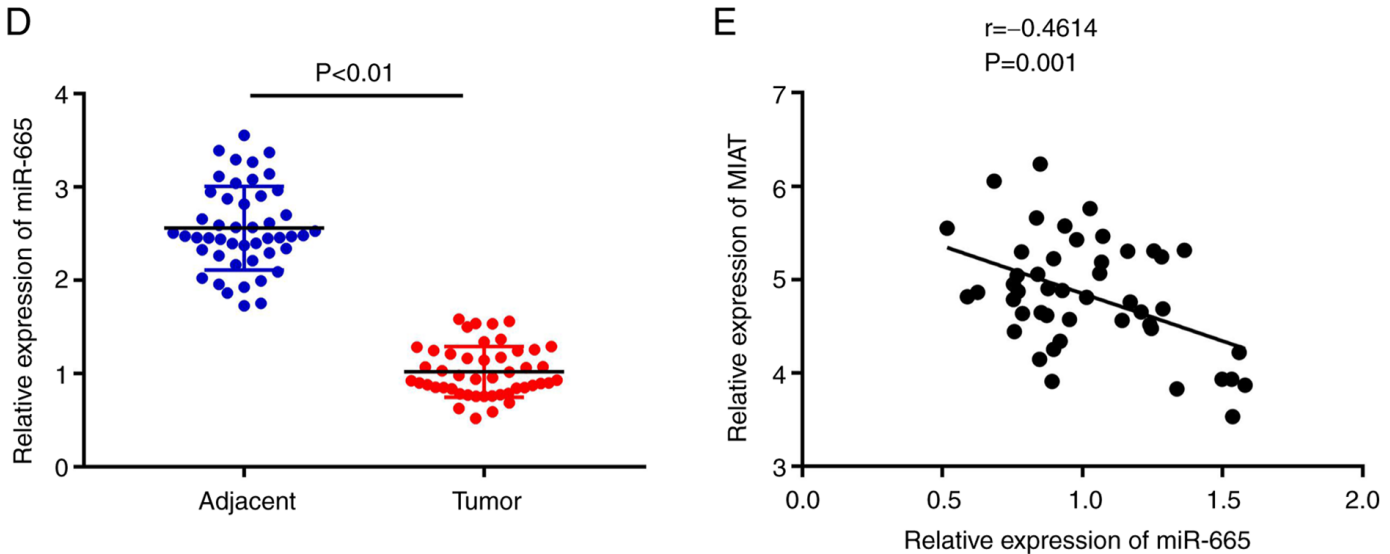

Figure 3. MIAT acts as an endogenous sponge of miR-665. (A) Predicted complementary binding site of MIAT and miR-665. (B) Luciferase activity in Rb cells co-transfected with pGL3-MIAT wt/pGL3-MIAT mut and miR-665 mimics/NC was determined by dual luciferase reporter assay. ${ }^{* *} \mathrm{P}<0.01$ vs. miR-NC group. (C) Expression of miR-665 following transfection with sh-MIAT/sh-NC in Rb cells was detected by RT-qPCR. ${ }^{* *} \mathrm{P}<0.01$ vs. sh-NC group. (D) Expression of miR-665 in tumour tissues $(n=47)$ and adjacent tissues $(n=47)$ was detected by RT-qPCR. (E) Correlation analysis between miR-665 and MIAT in Rb tissues. MIAT, myocardial infarction associated transcript; miR, microRNA; mut, mutant; wt, wild-type; NC, negative control; Rb, retinoblastoma; RT-qPCR, reverse transcription-quantitative PCR; sh, short hairpin.

revealed that MIAT downregulation has an inhibitory effect on the proliferation and migration of CC cells in vitro (14). The present study therefore hypothesized that MIAT silencing may inhibit the progression of $\mathrm{Rb}$.

Increasing research efforts have been engaged to elucidate the anti-tumour roles of miR-665 in human cancer (38-40). For example, miR-665 downregulation was reported to reverse the suppressive effects of the lncRNA RHPN1-AS1 on the proliferation and migratory and invasive abilities of OC cells (38).
Furthermore, transfection with miR-665 inhibitor partly aggravates the tumorigenicity of CRC in vitro (39). A recent study by $\mathrm{Wu}$ et al (40) revealed that miR-665 expression is downregulated in GC tissues, and that miR-665 overexpression exhibits a visible effect on tumour inhibition. In the present study, a decreased expression of miR-665 was found in Rb tissues, and miR-665 overexpression significantly reduced the proliferation and migratory and invasive abilities of Rb cells. Similarly, Wang et al (23) reported that miR-665 is minimally expressed 

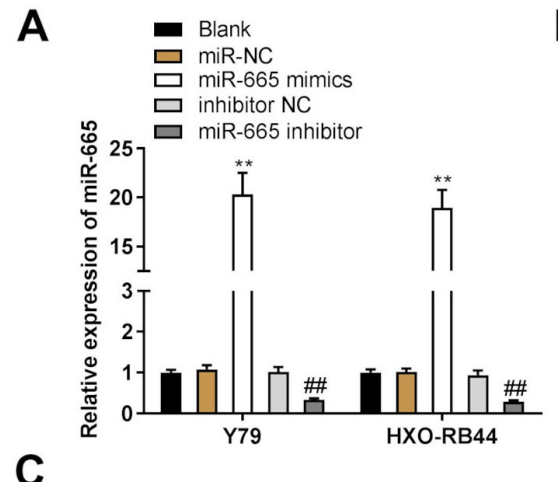

B
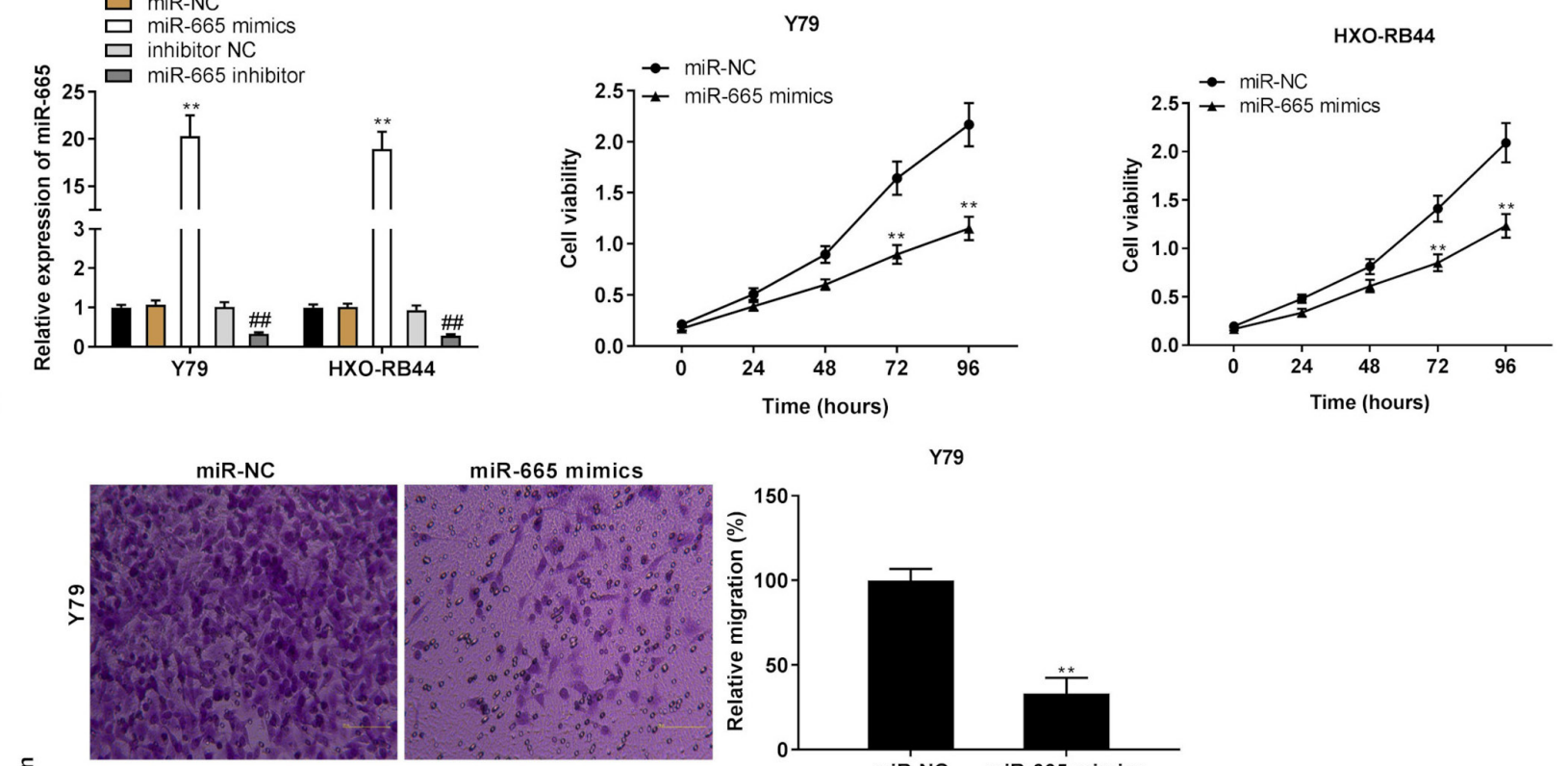

miR-665 mimics
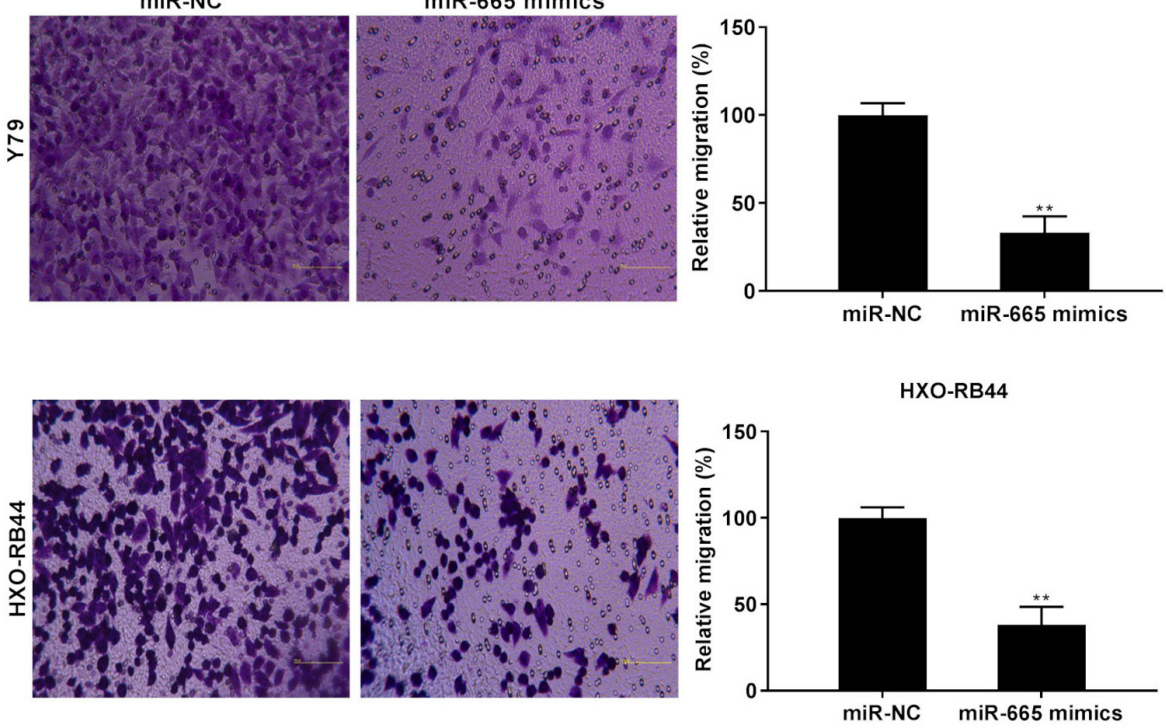

D
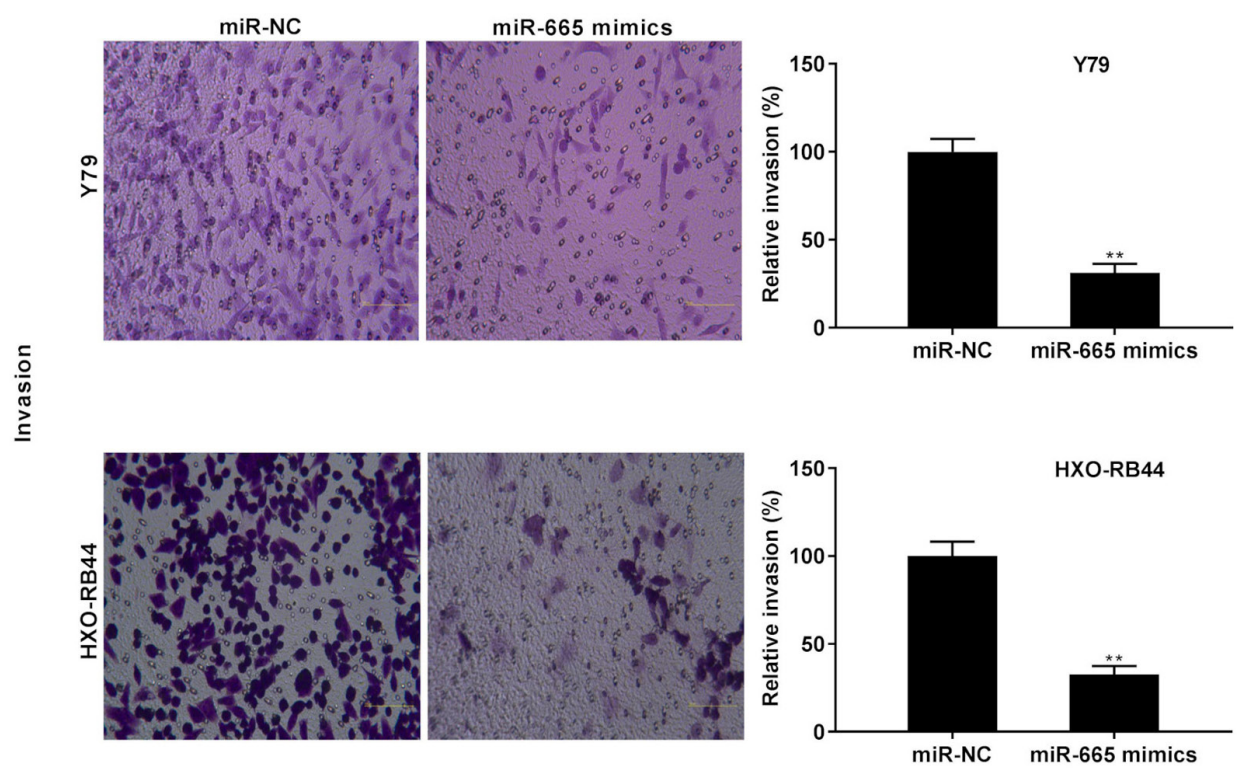

Figure 4. High expression of miR-665 can inhibit the proliferation and migratory and invasive abilities of Rb cell lines in vitro. (A) Expression of miR-665 following transfection with miR-665 mimics/miR-NC or miR-665 inhibitor/inhibitor NC in Rb cells was detected by reverse transcription-quantitative PCR. ${ }^{* *} \mathrm{P}<0.01$ vs. miR-NC group; ${ }^{\# \#} \mathrm{P}<0.01$ vs. inhibitor group. (B) Rb cell viability was evaluated using MTT assay. (C) Migratory ability of Rb cells was measured by Transwell assay. (D) Invasive ability of Rb cells was measured by Transwell assay. ${ }^{* *} \mathrm{P}<0.01$ vs. miR-NC group. miR, microRNA; NC, negative control; $\mathrm{Rb}$, retinoblastoma; OD, optical density.

in $\mathrm{Rb}$ tissues and cell lines, and that the proliferation and migratory and invasive abilities of $\mathrm{Rb}$ cells are inhibited following transfection with miR-665 mimics. In the present study, MIAT was shown to target and negatively modulate miR-665 
A

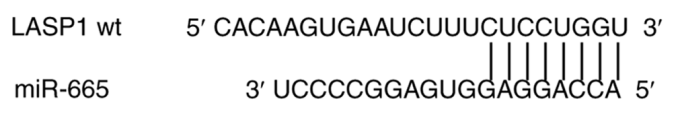

B

LASP1 mut 5' CACAAGUGAAUCUUUGAGGACCA 3'
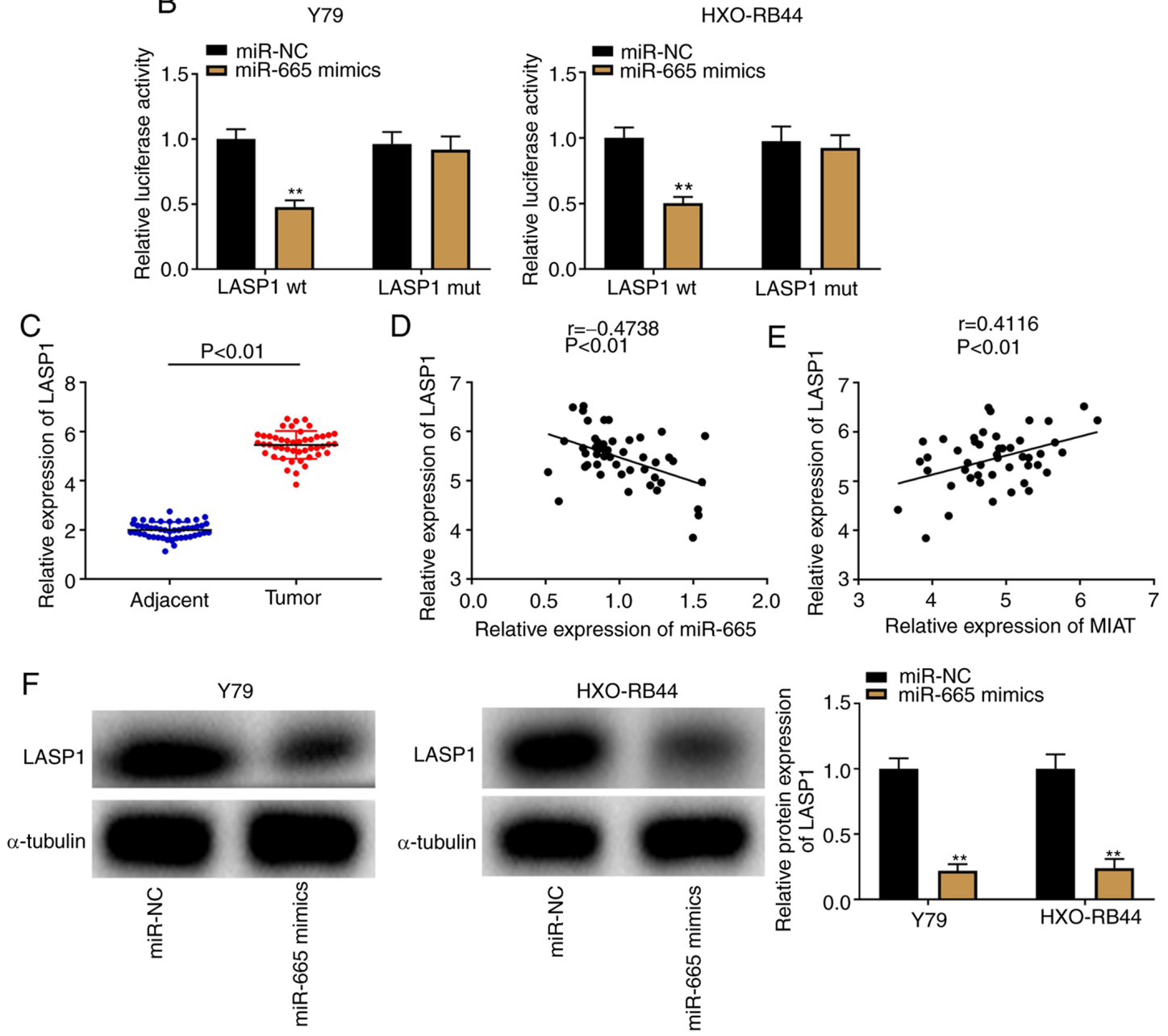

Figure 5. Identification of LASP1 as a downstream target gene of miR-665. (A) Predicted complementary binding site of LASP1 and miR-665. (B) Luciferase activity in Rb cells co-transfected with pGL3-LASP1 wt/pGL3-LASP1 mut and miR-665 mimics/miR-NC was determined by dual luciferase reporter assay. ${ }^{* *} \mathrm{P}<0.01$ vs. miR-NC group. (C) Expression of LASP1 in tumour tissues $(\mathrm{n}=47)$ and adjacent tissues $(\mathrm{n}=47)$ was detected by RT-qPCR. (D) Correlation analysis between miR-665 and LASP1 expression in Rb tissues. (E) Correlation analysis between MIAT and LASP1 in Rb tissues. (F) Protein expression of LASP1 in $\mathrm{Rb}$ cells following transfection with miR-665 mimics was detected by western blotting. ${ }^{* *} \mathrm{P}<0.01 \mathrm{vs}$. miR-NC group. MIAT, myocardial infarction associated transcript; miR, microRNA; mut, mutant; wt, wild-type; NC, negative control; Rb, retinoblastoma; RT-qPCR, reverse transcription-quantitative PCR; sh, short hairpin; LASP1, LIM and SH3 protein 1.

expression, suggesting that miR-665 may be involved in $\mathrm{Rb}$ tumorigenesis via MIAT regulation. The results of the present study further demonstrated that the decreased expression of miR-665 reversed the inhibitory effects of MIAT silencing on the proliferation and migratory and invasive abilities of Y79 cells. These findings indicated that MIAT knockdown may attenuate $\mathrm{Rb}$ malignancy by modulating miR- 665 .

LASP1, an oncogene involved in cancer aggressiveness (41), was found to be upregulated in numerous types of cancer, including gallbladder cancer (42), NSCLC (43), CRC (44) and OC (45). In the present study, LASP1 was demonstrated to be highly expressed in $\mathrm{Rb}$ tissues compared with that in adjacent tissues. Consistent with these findings, Yang et al (8) reported a high expression level of LASP1 in Rb tissues. These results suggested that LASP1 may act as an oncogene in $\mathrm{Rb}$ pathogenesis. Furthermore, a positive correlation between
MIAT and LASP1 expression was observed in the present study. Similarly, Liu et al (46) confirmed that the expression of LASP1 is positively correlated with MIAT expression in papillary thyroid cancer tissues. Furthermore, the present study demonstrated that LASP1 may be a target gene of miR-665 and was negatively regulated by miR- 665 . These findings suggested that miR-665 may be involved in the tumorigenesis of $\mathrm{Rb}$ via MIAT regulation. We hypothesized that LASP1 may be modulated by MIAT and be involved in Rb progression. The feedback verification experiments demonstrated that the enhancement of proliferation and migratory and invasive abilities of Y79 cells caused by MIAT silencing were restrained following transfection with pcDNA-LASP1, which confirmed this hypothesis. These findings indicated that MIAT downregulation may reduce the progression of $\mathrm{Rb}$ by sponging miR-665 and regulating LASP1. 
A

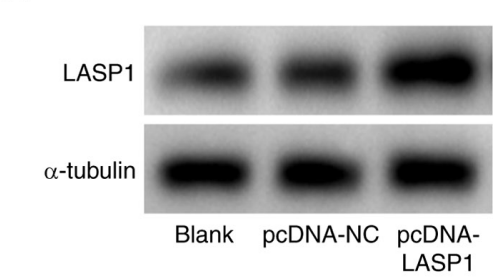

Y79

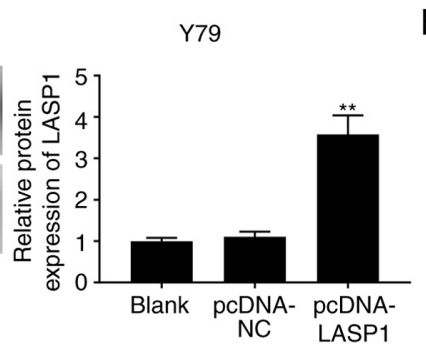

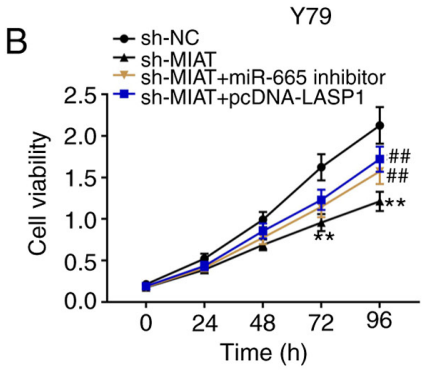
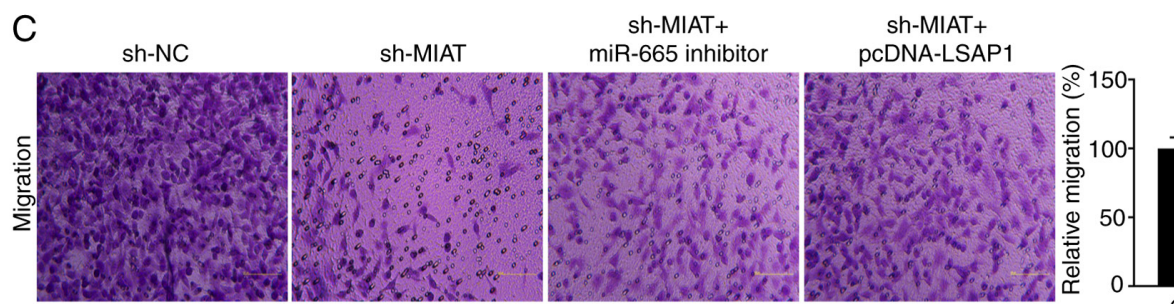

Y79

D
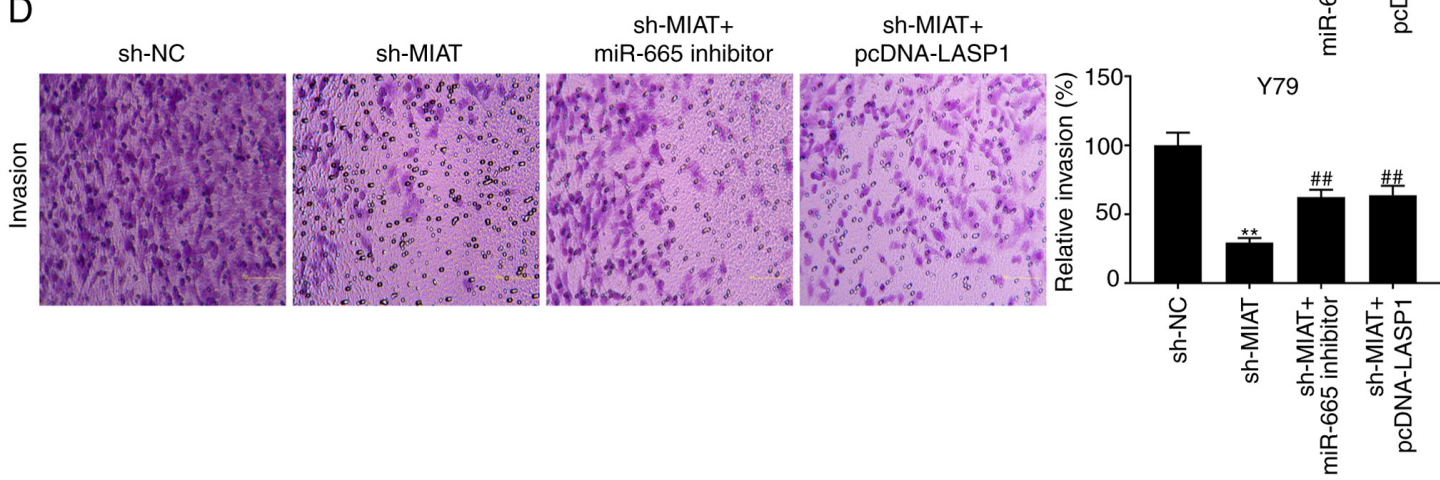

Figure 6. MIAT knockdown delays the development of Rb through sponging miR-665 and regulating LASP1. (A) Protein expression of LASP1 following transfection with pcDNA-LASP1/NC into Y79 cells was determined by western blotting. ${ }^{* *} \mathrm{P}<0.01 \mathrm{vs.} \mathrm{pcDNA-NC}$ group. (B) Y79 cell viability was evaluated using an MTT assay. (C) Migratory ability of Rb cells was measured by Transwell assay. (D) Invasive ability of Rb cells was measured by Transwell assay. ${ }^{* *} \mathrm{P}<0.01$ vs. sh-NC group; ${ }^{\# \#} \mathrm{P}<0.01$ vs. sh-MIAT group. MIAT, myocardial infarction associated transcript; miR, microRNA; NC, negative control; Rb, retinoblastoma; sh, short hairpin; LASP1, LIM and SH3 protein 1; OD, optical density.

In summary, the present study reported an elevated expression level of MIAT in Rb tissues and demonstrated that MIAT silencing significantly reduced the tumorigenicity of $\mathrm{Rb}$ by modulating the miR-665/LASP1 axis in vitro. The results from this study provide a novel target for treating $\mathrm{Rb}$ and may be applied in the clinical setting. One limitation of this study is the absence of in vivo experiments to confirm the interactions among MIAT, miR-665 and LASP1. Further investigation will therefore be performed in the future.

\section{Acknowledgements}

Not applicable.

\section{Funding}

No funding was received.

\section{Availability of data and materials}

The datasets used and/or analyzed during the current study are available from the corresponding author on reasonable request.

\section{Authors' contributions}

$\mathrm{XX}$ and BD made significant contributions to the overall structure design of the study, data analysis, methodology, project management, funding and draft writing. YZ and GD are mainly responsible for resource collection and integration, experiments, experimental data analysis, software processing and paper modification and editing. All authors confirmed the authenticity of all the raw data and have read and approved the final manuscript.

\section{Ethics approval and consent to participate}

This study was performed in line with the principles of the Declaration of Helsinki. Approval was granted by the Ethics Committee of No. 215 Hospital of Shaanxi Nuclear Industry (approval no. EC-20200924-1017). Each patient or their parents provided written informed consent.

\section{Patient consent for publication}

Not applicable. 


\section{Competing interests}

The authors declare that they have no competing interests.

\section{References}

1. Pascual-Pasto G, Bazan-Peregrino $\mathrm{M}$, Olaciregui NG, Restrepo-Perdomo CA, Mato-Berciano A, Ottaviani D, Weber K, Correa G, Paco S, Vila-Ubach M, et al: Therapeutic targeting of the RB1 pathway in retinoblastoma with the oncolytic adenovirus VCN-01. Sci Transl Med 11: 11, 2019.

2. Chantada GL, Qaddoumi I, Canturk S, Khetan V, Ma Z, Kimani K, Yeniad B, Sultan I, Sitorus RS, Tacyildiz N, et al: Strategies to manage retinoblastoma in developing countries. Pediatr Blood Cancer 56: 341-348, 2011.

3. CanturkS,QaddoumiI,KhetanV,MaZ,FurmanchukA,AntoneliCB, Sultan I, Kebudi R, Sharma T, Rodriguez-Galindo C, et al: Survival of retinoblastoma in less-developed countries impact of socioeconomic and health-related indicators. Br J Ophthalmol 94: 1432-1436, 2010.

4. Errico A: Cancer therapy: Retinoblastoma - chemotherapy increases the risk of secondary cancer. Nat Rev Clin Oncol 11: 623, 2014.

5. Shields CL, Say EA, Pointdujour-Lim R, Cao C, Jabbour PM and Shields JA: Rescue intra-arterial chemotherapy following retinoblastoma recurrence after initial intra-arterial chemotherapy. J Fr Ophtalmol 38: 542-549, 2015.

6. Rao AKDM, Rajkumar T and Mani S: Perspectives of long non-coding RNAs in cancer. Mol Biol Rep 44: 203-218, 2017.

7. Li S, Wen D, Che S, Cui Z, Sun Y, Ren H and Hao J: Knockdown of long noncoding RNA 00152 (LINC00152) inhibits human retinoblastoma progression. OncoTargets Ther 11: 3215-3223, 2018.

8. Yang L, Zhang L, Lu L and Wang Y: Long noncoding RNA SNHG16 sponges miR-182-5p and miR-128-3p to promote retinoblastoma cell migration and invasion by targeting LASP1 OncoTargets Ther 12: 8653-8662, 2019.

9. Wu XZ, Cui HP, Lv HJ and Feng L: Knockdown of lncRNA PVT1 inhibits retinoblastoma progression by sponging miR-488-3p. Biomed Pharmacother 112: 108627, 2019.

10. Wang L, Wang C, Wu T and Sun F: Long non-coding RNA TP73-AS1 promotes TFAP2B-mediated proliferation, metastasis and invasion in retinoblastoma via decoying of miRNA-874-3p. J Cell Commun Signal 14: 193-205, 2020.

11. Chang W, Wang Y, Li W and Geng Z: Long non-coding RNA myocardial infarction associated transcript promotes the proliferation of cholangiocarcinoma cells by targeting miR-551b-3p/CCND1 axis. Clin Exp Pharmacol Physiol 47: $1067-1075,2020$

12. Zhou Z, Zhang S and Xiong Y: Long noncoding RNA MIAT promotes non-small cell lung cancer progression by sponging miR-149-5p and regulating FOXM1 expression. Cancer Cell Int 20: 348, 2020

13. Li F, Li H, Li S, Lv B, Shi J, Yan H, Zhang H and He Y: Long Non-coding RNA MIAT mediates non-small cell lung cancer development through regulating the miR-128-3p/PELI3 Axis. Biochem Genet 58: 867-882, 2020.

14. Zhang L, Ge S and Cao B: Long non-coding RNA MIAT promotes cervical cancer proliferation and migration. J Biochem 168 : 183-190, 2020.

15. Zhou S, Xu A, Song T, Gao F, Sun H and Kong X: lncRNA MIAT regulates cell growth, migration, and invasion through sponging miR-150-5p in ovarian cancer. Cancer Biother Radiopharm 35: 650-660, 2020

16. Liu Y, Peng H, Shen Y, Da R, Tian A and Guo X: Downregulation of long noncoding RNA myocardial infarction associated transcript suppresses cell proliferation, migration, invasion, and glycolysis by regulation of miR-488-3p/IGF1R pathway in colorectal cancer. Cancer Biother Radiopharm: Oct 21, 2020 (Epub ahead of print). doi: 10.1089/cbr.2020.3671.

17. Sha M, Lin M, Wang J, Ye J, Xu J, Xu N and Huang J: Long non-coding RNA MIAT promotes gastric cancer growth and metastasis through regulation of miR-141/DDX5 pathway. J Exp Clin Cancer Res 37: 58, 2018.

18. Lu TX and Rothenberg ME: MicroRNA. J Allergy Clin Immunol 141: 1202-1207, 2018.

19. Liu Y, Li H, Liu Y and Zhu Z: MiR-22-3p targeting alpha-enolase 1 regulates the proliferation of retinoblastoma cells. Biomed Pharmacother 105: 805-812, 2018
20. Wang L, Yang D, Tian R and Zhang H: NEAT1 promotes retinoblastoma progression via modulating miR-124. J Cell Biochem 120: 15585-15593, 2019.

21. Han N, Zuo L, Chen H, Zhang C, He P and Yan H: Long non-coding RNA homeobox A11 antisense RNA (HOXA11-AS) promotes retinoblastoma progression via sponging miR-506-3p. OncoTargets Ther 12: 3509-3517, 2019.

22. Xu L, Li W, Shi Q, Wang M, Li H, Yang X and Zhang J: MicroRNA 936 inhibits the malignant phenotype of retinoblastoma by directly targeting HDAC 9 and deactivating the PI3K/AKT pathway. Oncol Rep 43: 635-645, 2020.

23. Wang S, Du S, LV Y, Zhang F and Wang W: MicroRNA-665 inhibits the oncogenicity of retinoblastoma by directly targeting high-mobility group box 1 and inactivating the Wnt/ $\beta$-catenin pathway. Cancer Manag Res 11: 3111-3123, 2019.

24. Zhang S, Long J and Hu Y: Long noncoding RNA LINC00205 enhances the malignant characteristics of retinoblastoma by acting as a molecular sponge of microRNA-665 and consequently increasing HMGB1 expression. Biochem Biophys Res Commun 526: 396-403, 2020.

25. Hu S, Ran Y, Chen W, Zhang Y and Xu Y: MicroRNA-326 inhibits cell proliferation and invasion, activating apoptosis in hepatocellular carcinoma by directly targeting LIM and SH3 protein 1. Oncol Rep 38: 1569-1578, 2017.

26. Yan P, Liu J, Zhou R, Lin C, Wu K, Yang S, Yang S, Zhou J, $\mathrm{Xu}$ L, Wang $\mathrm{H}$, et al: LASP1 interacts with N-WASP to activate the Arp $2 / 3$ complex and facilitate colorectal cancer metastasis by increasing tumour budding and worsening the pattern of invasion. Oncogene 39: 5743-5755, 2020.

27. Wang S, Qiu J, Wang L, Wu Z, Zhang X, Li Q and Jiang F: Long non-coding RNA LINC01207 promotes prostate cancer progression by downregulating microRNA-1972 and upregulating LIM and SH3 protein 1. IUBMB Life 72: 1960-1975, 2020.

28. Sui Y, Zhang X, Yang H, Wei W and Wang M: MicroRNA-133a acts as a tumour suppressor in breast cancer through targeting LASP1. Oncol Rep 39: 473-482, 2018.

29. Song X, Jin Y, Yan M, Zhang Y and Chen B: MicroRNA-342-3p functions as a tumor suppressor by targeting LIM and SH3 protein 1 in oral squamous cell carcinoma. Oncol Lett 17: 688-696, 2019.

30. Liu W, Wang ZL, Wang C and Ai ZL: Long non-coding RNA MIAT promotes papillary thyroid cancer progression through upregulating LASP1. Cancer Cell Int 19: 194, 2019.

31. Wang JX, Yang Y and Li K: Long noncoding RNA DANCR aggravates retinoblastoma through miR-34c and miR- 613 by targeting MMP-9. J Cell Physiol 233: 6986-6995, 2018.

32. Shang W, Yang Y, Zhang J and Wu Q: Long noncoding RNA BDNF-AS is a potential biomarker and regulates cancer development in human retinoblastoma. Biochem Biophys Res Commun 497: 1142-1148, 2018.

33. Yan $\mathrm{G}, \mathrm{Su}$ Y, Ma Z, Yu L and Chen N: Long Noncoding RNA LINC00202 promotes tumor progression by sponging miR-3619-5p in retinoblastoma. Cell Struct Funct 44: 51-60, 2019.

34. Hu C, Liu S, Han M, Wang Y and Xu C: Knockdown of lncRNA XIST inhibits retinoblastoma progression by modulating the miR-124/STAT3 axis. Biomed Pharmacother 107: 547-554, 2018.

35. Livak KJ and Schmittgen TD: Analysis of relative gene expression data using real-time quantitative PCR and the 2(-Delta Delta C(T)) Method. Methods 25: 402-408, 2001.

36. Du Z, Sun T, Hacisuleyman E, Fei T, Wang X, Brown M, Rinn JL, Lee MG, Chen Y, Kantoff PW, et al: Integrative analyses reveal a long noncoding RNA-mediated sponge regulatory network in prostate cancer. Nat Commun 7: 10982, 2016.

37. Hao F, Mou Y, Zhang L, Wang S and Yang Y: LncRNA AFAP1-AS1 is a prognostic biomarker and serves as oncogenic role in retinoblastoma. Biosci Rep 38: 38, 2018.

38. Zhao J, Yang T, Ji J, Zhao F, Li C and Han X: RHPN1-AS1 promotes cell proliferation and migration via miR-665/Akt3 in ovarian cancer. Cancer Gene Ther 28: 33-41, 2021.

39. Ouyang S, Zhou X, Chen Z, Wang M, Zheng X and Xie M: LncRNA BCAR4, targeting to miR-665/STAT3 signaling, maintains cancer stem cells stemness and promotes tumorigenicity in colorectal cancer. Cancer Cell Int 19: 72, 2019.

40. Wu KZ, Zhang CD, Zhang C, Pei JP and Dai DQ: miR-665 suppresses the epithelial-mesenchymal transition and progression of gastric cancer by targeting CRIM1. Cancer Manag Res 12: 3489-3501, 2020.

41. Orth MF, Cazes A, Butt E and Grunewald TG: An update on the LIM and SH3 domain protein 1 (LASP1): A versatile structural, signaling, and biomarker protein. Oncotarget 6: 26-42, 2015. 
42. Li Z, Chen Y, Wang X, Zhang H, Zhang Y, Gao Y, Weng M, Wang L, Liang H, Li M, et al: LASP-1 induces proliferation, metastasis and cell cycle arrest at the $\mathrm{G} 2 / \mathrm{M}$ phase in gallbladder cancer by down-regulating S100P via the PI3K/AKT pathway. Cancer Lett 372: 239-250, 2016.

43. Zheng J, Wang F, Lu S and Wang X: LASP-1, regulated by miR-203, promotes tumor proliferation and aggressiveness in human non-small cell lung cancer. Exp Mol Pathol 100: 116-124, 2016.

44. Zhao L, Wang H, Liu C, Liu Y, Wang X, Wang S, Sun X, Li J, Deng Y, Jiang Y, et al: Promotion of colorectal cancer growth and metastasis by the LIM and SH3 domain protein 1. Gut 59: $1226-1235,2010$
45. Grunewald TG, Kammerer U, Winkler C, Schindler D, Sickmann A, Honig A and Butt E: Overexpression of LASP-1 mediates migration and proliferation of human ovarian cancer cells and influences zyxin localisation. Br J Cancer 96: 296-305, 2007.

46. Liu W, Wang Z, Wang C and Ai Z: Long non-coding RNA MIAT promotes papillary thyroid cancer progression through upregulating LASP1. Cancer Cell Int 19: 194, 2019. 